\title{
Effects of Restaurant Interior Elements on Social Dining Behavior
}

\author{
Prabu Wardono, Haruo Hibino, Shinichi Koyama \\ Graduate School of Engineering., Chiba University , Japan \\ prabu@graduate.chiba-u.jp
}

\begin{abstract}
Today's customers tend to select eating-places to satisfy pleasures through experiential socialization. This study explores how colors, lighting and décor have effects on customers' perceived social, emotional and behavioral intention on social dining occasions. The experimental method is used and 162 senior students are involved. The results show that the restaurant with monochromatic color scheme, dim lighting and plain décors yield a statistically significant difference on the entire dependent variables with almost any other interior conditions observed on romantic dining, as opposed to that in the case of casual dining. Further research on subtler and diverse dimensions of interior element is suggested to enrich previous findings.
\end{abstract}

Keywords: Interior elements, perceived sociability, emotion, social dining behaviour.

eISSN 2514-751X @ 2017 The Authors. Published for AMER ABRA by e-International Publishing House, Ltd., UK.. This is an open access article under the CC BY-NC-ND license (http://creativecommons.org/licenses/by-ncnd/4.0/). Peer-review under responsibility of AMER (Association of Malaysian Environment-Behaviour Researchers), ABRA (Association of Behavioural Researchers on Asians) and cE-Bs (Centre for EnvironmentBehaviour Studies), Faculty of Architecture, Planning \& Surveying, Universiti Teknologi MARA, Malaysia.

https://doi.org/10.21834/aje-bs.v2i4.209 


\subsection{Introduction}

Foods and drinks were abundantly and ubiquitously offered after the post-industrialization era. Since then, consumer motives of consumption had shifted from meeting our basic nutritional needs to a more pleasurable experience (Macht, Meininger, \& Roth, 2005).

The development of atmospheric eating-places has gained more interests among restaurant owners to attract customers who seek exceptional and extraordinary places for leisure (Scott, Laws, \& Boksberger, 2009). In such economic situation, retail business investors are focusing their attention on innovating their goods and services to try to transform them into experienced products that are memorable to customers (Pine II \& Gilmore, 1998). These authors found five key experience design principles for designing memorable experience including: "1. Theme the experience, 2. Harmonize impressions with positive cues, 3. Eliminate negative cues, 4. Mix in memorabilia, 5. Engage all five senses". Among eating activities, hedonic eating may represent the need for memorable eating experience, where stimuli consisting of foods, physical environment and social factors as human external factors play a role in satisfying customers (Macht et al., 2005). These authors elaborate that environmental condition including temperature, lighting, and acoustic should be set up appropriately to support pleasurable eating. In addition, the presence of familiar eating partners such as the family, friends or special friends will increase appetite and pleasure identified through psychological manifestations like eating behavior and subjective experiences, besides other more physical responses. Supporting this, Wansink (2006) said that pleasurable moments can be attained when we share foods with the family or friends. Various kinds of eating-places like cafés, or bistros and the like termed as third place (Oldenburg, 1997) might be developed for casual gathering. The way people socialize depends on their innate characteristic and learning ability since childhood (Flanagan, 1999), therefore the place suitable for their socialization may differ. Unfortunately, research on consumer social behavior related to eating-places is very scarce. Therefore, how eatingplaces can satisfy and cultivate customer social life may not easily be answered.

Colors, lighting and décor as some of common major elements of servicescape are explored and this leads to questions on how these elements support people's dining intention with a friend/s and with a special friend? Which of these elements play the most significant role to encourage sociability? We assume that participants would be more satisfied if their positive responses are higher. Based on this assumption, we propose two hypotheses as follows:

\section{Hypothesis 1:}

The change of variable of interior elements will have a significant effect on the subjects' psychological responses on dining with a friend/s.

Hypothesis 2:

The change of variable of interior elements will have a significant effect on the subjects' psychological responses on dining with a special friend. 


\subsection{Literature Review}

Sociability is part of five basic inborn personality attributes along with "activity level, irritability or emotionality, soothability and fearfulness" Goldsmith et al. (1987) said as Flanagan (1999) quoted, the human complexity of which might be even more when people are incidentally placed with unexpected environmental influences. For example, environmental stress such as severe temperature, humidity, ventilation, vibration, noise and glare may all become irritating for a couple to talk (Wheldall, 1975).

In terms of how environmental settings support orientation of people when talking, Gifford and Gallagher (1985) theorized that besides person-based variables and social context, physical settings were important factors, which influenced how people socialized. They regulate how furniture arrangement supports conversation effectively. Besides, people also need to judge an environment according to their perception and emotional response before, during and after they experience it. In response to this, a research done by Lin (2004) found that servicescapes offered a subsequent impression to the customers before being served. But, this does not explain how customers react cognitively or emotionally to servicescape. Ryu and Jang (2007) using structural equation modeling analysis found that facility aesthetics, involving visual cues like: furniture, color, lighting and décor, ambience (non visual cues) and employees influenced significantly on the level of customer pleasure, and particularly ambience and employees gave impact significantly to arousal. Liu and Jang (2009) using an extended model of Mehrabian and Russel model proved that all the environmental features of a restaurant, tangible or intangible one gave significant impact to those psychological responses of customers. They concluded that it was vital to consider the effect of restaurant atmosphere to enhance customers' perceived value to ensure their return patronage. However, these studies did not cover a particular dining motive to determine the success of restaurant. The existence of a restaurant is now a spatial representation of social formation where people, a couple of friends, relatives or lovers meet (Diane, 2005). Good company either as customer's eating companion/s or other guests is considered the most important factor to predict dining experience for the latter can become an important reference of how customers expect from the restaurant in terms of financial value, said Anderson and Mossberg (2004) as quoted by Azizi (2010).

From the above reviews it is obvious that perception, emotion and behaviour of customers as well as the presence of their eating companions are important sociopsychological factors that determine their eating experience satisfaction. But there is no detailed explanation how service environment should be prepared to achieve that goal in the context of social eating intention.

\subsection{Methodology}

\subsection{Participants and design of experiment}


Participants were 162 senior students, aged between 19 and 22 years of age, selected from 395 students according to their willingness for participation. They were then grouped into eight groups of 20 and 22. In return for their participation, a voucher of beverage at a café was given as a compliment.

To answer the research questions, an experimental method specifically stimulus response experiment was applied. Three factors of restaurant interior environment including colors, lighting and décors were examined, and in order to study more detail on them, each of these factors was developed into two levels making up all these factors into eight different conditions, as independent variables, described in detail later. The dependent variables were psychological factors consisting of perceived sociability, emotional response and behavioral intention, which were prepared in a questionnaire and to be filled in by the participants during the experiment. Eight groups of participants of 20 and 22 were independently assigned to value eight different pictures (between subject design) according to the psychological responses described above.Each group carried out two trials; first, evaluate one picture in the context of dining with a friend/s and the second, in the context of dining with a special friend.

\subsection{Stimulus, questionnaire and facility}

In this experiment, we used a digital simulation using 3D-Max computer software to create eight different pictures of restaurant interior atmosphere based on one model of restaurant and combination of two levels of color scheme: monochromatic colors and complementary colors, lighting: bright lighting and dim lighting, and décor: elaborate décor and plain décor respectively as the experimental stimuli, see Figure 1-8. This model shows a corner of casual restaurant interior with slightly low ceiling. Some sets of chairs and tables with tablecloth were fixed arranged and individually illuminated using pendant lamp and all this made the room look accessible, simple and informal (Oldenburg,1997).

Each picture differs from one another only in one type of variable. The color schemes applied in these pictures were defined according to some principles of Munsell color harmony. The color specifications adopted Adobe RGB (1998) standard colors were also applied by some researchers like, Cheng, Lee and Lee (2007) and Junko, Masashi, and Minoru (2006), and this can also refer to chromaticity coordinates.(see Appendix) Besides the color variable specified above, the lighting element applied a different lamp and light setting in the computer. In the case of bright-lighted restaurants, the lamps and light setting applied a fluorescent (day light) and $15.000 \mathrm{~lm}$, and in the case of dim lighted restaurants used fluorescent (warm white) and $5.000 \mathrm{Im}$. The décor (the paintings, plants, lighting armature and table cloth) was practically differentiated by considering the number and quality of decorative elements (elaborate and plain) applied. 


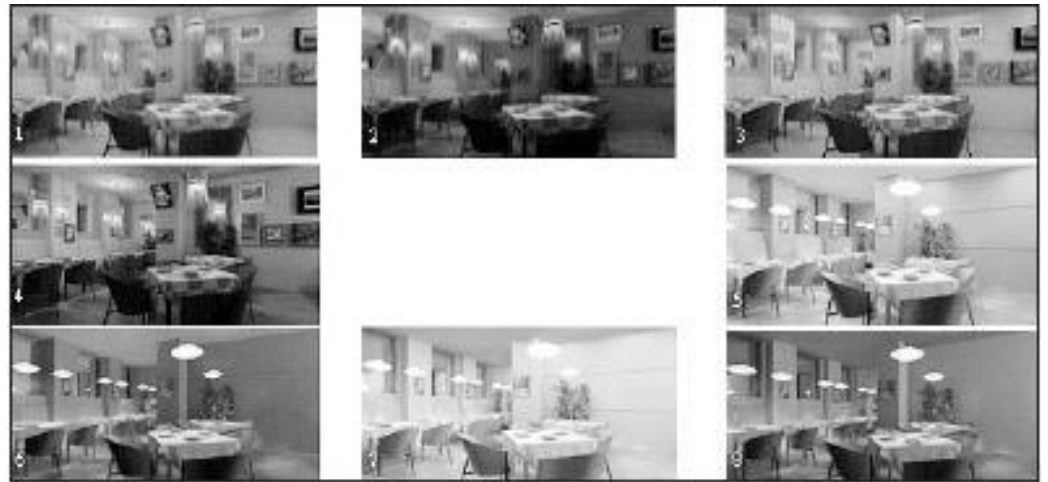

Figure 1- 8 Experimental stimuli: 1. Monochromatic colors, bright lighting, and elaborate décor 2. Monochromatic colors, dim lighting, and elaborate décor, 3. Complementary colors, bright lighting, and elaborate décor 4. Complementary colors, dim lighting, and elaborate décor 5. Monochromatic colors, bright lighting, and plain décor 6 . Monochromatic colors, dim lighting, and plain décor 7 . Complementary colors, bright lighting, and plain décor, 8. Complementary colors, dim lighting, and plain décor.

The relevant literature and experts referred to develop how behavioral variables were measured includes Mehrabian and Russel (1974) and Ryu et al. (2007). Interviews with two groups of three senior students were conducted to find valuable clues related to their social dining experiences. As a result, a questionnaire containing three sets of psychological response were defined including, perceived sociability, emotional response and behavioral intention, consisting of, first (15 paired adjectival words): "appealing, attractive, welcoming, friendly, warm, hospitable, cozy, secure, private, convenient, homey, intimate, casual, familiar and unique", second (8 paired adjectival words): "happy, satisfied, bored, melancholic, awake, aroused, excited, and stimulated" and third (3 paired behavioral statements): "want to revisit several times, linger long and do not mind to wait long". These variables were measured using seven point-scale semantic differential methods (+3 to -3$)$.

To accommodate this study, a lighting lab of around $4 \times 4 \mathrm{~m} 2$, at Human-Environment relationship research unit, Faculty of Fine Art and Design, Bandung Institute of Technology, Indonesia, was used for conducting the experiment. In addition, table lamps were also provided for the participants to fill in the questionnaires. Four tables, chairs and equipments were provided for the subjects and researcher. The equipments used for the experiment were a new 2000 lumen SONY video projector (VPL-ES7), MacBook laptop (Mac OSX Version 10.5.8, Processor $2.4 \mathrm{GHz}$ Intel Core 2 Duo, Memory $2 \mathrm{~GB}, 667 \mathrm{MHz}$, DDR2

\subsection{Experimental Procedure}

The picture was projected to the screen at around $2.5 \mathrm{~m}$ distance away from where the subjects sit. Each of the groups was independently assigned and was only observed and 
rated one picture (between subject design). The order of presentation per session or day was not tightly regulated as it depended so much on the students' time availability, but since every group was independent, basically the presentation could be flexibly conducted. The presentation of picture was also not timely limited as we expected that the participants could observe it very carefully to ensure more convincing responses they could give.

\subsection{Results And Discussions}

The mean scores of perceived sociability, emotional response, and behavioral intention on dining with a friend/s and with a special friend can be seen on Figure 9, Figure 10 and Figure 11 respectively below.

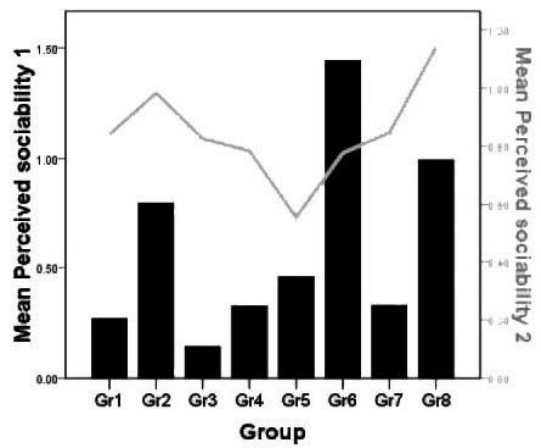

Figure 9: Mean scores of perceived sociability on dining with a friends/s and dining with a special friend

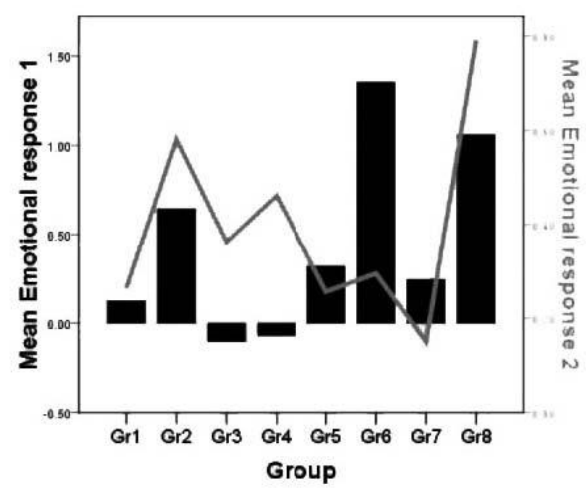

Figure 10: Mean scores of emotional response on dining with a friend/s and dining with a special friend 


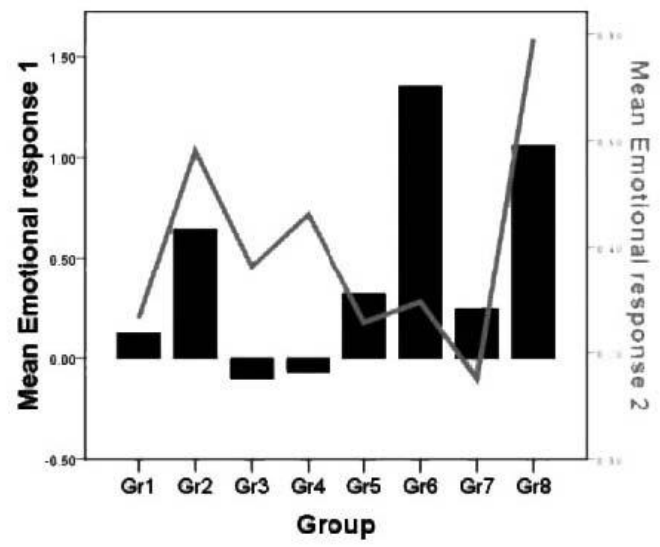

Figure 11: Mean scores of behavioral intention on dining with a friend/s and dining with a special friend

Anova test's results showed that the change of interior condition in the case of dining with a friend/s did not show any statistically significant effect in all the variables on the subjects perceived sociability $(F=.802, P=.587)$, emotional response $(F=.969, P=.456)$, and behavioral intention ( $F=.571, P=.779$ ) respectively.

In the context of dining with a special friend, the change of interior condition yielded a very significant effect in the entire variables between some groups: perceived sociability $(F=4.366, P=.000)$, emotional response $(F=5.007, P=.000)$, and behavioral intention $(F=6.698, P=.000)$ respectively. The interior condition of group 6 applying monochromatic colors, dim lighting and plain décor resulted in a statistically significant difference in perceived sociability compared with the entire restaurant conditions, including with group 1 (Mean diff:: 9.800, $\mathrm{P}=.009$ ), group 3 (Mean diff.=11.600, $\mathrm{P}=.001$ ), group 4 (Mean diff. 11.350, $P=.001$ ), group 7 (Mean diff. $=8.850, P=.027$ ), but not with group 2 (Mean diff. $=5.650, P=.422$ ), group 5 (Mean diff. $=8.250, P=.052$ ) and group 8 (Mean diff. $=2.345$, $\mathrm{P}=.987$ ).

With regard to the emotional response, group 6 was also different significantly compared with group 1 (Mean Diff. $=2.850, P=.004$ ), group 3 (Mean diff.=19.450, $P=.001$ ), group 4 (Mean diff. $=16.700, P=.008$ ), group5 (Mean diff. $=14.700, P=.031$ ) and group 7 (Mean diff. 16.650, $\mathrm{P}=.008$ ), except with group 2 and group 8 . Compared to the previous result, only with group 5 was their result different. However, since the $P$ value of group 5 is .052 compared with group 6 , which is only a little larger than the significant score, it can be said that group 6 was regarded the same as the rest of the groups in perceived sociability and emotional response.

Similar to the previous variables, group 6 in behavioral intention showed a significant difference with almost the entire groups including with group 1 (Mean diff. $=4.900, P=.001$ ), 
group 2 (Mean diff. $=3.900, P=.024$ ), group 3 (Mean diff.=5.650, $P=.000$ ), group 4 (Mean diff.=5.700, $P=.000$ ), and group 7 (Mean diff. $=5.050, P=.001$ ), except with group 5 and group 8 (Mean diff.= 3.250, $P=.110$ and Mean diff. $=1.141, P=.974$ respectively).

Two tailed t-tests were also run to find out how the subjects valued of the restaurants on dining with a friend/s in comparison with that on dining with a special friend. In the case of perceived sociability, group $1(t=4.498, d f=19$, Sig. $=.000)$, group $3(t=2.944, d f=19$, Sig.=.008), group 4 ( $\mathrm{t}=-2.880$, df=19, Sig.=.008), group $6(\mathrm{t}=-2.718, \mathrm{df}=19$, Sig. $=.010)$ and group $7(\mathrm{t}=14.812, \mathrm{df}=19$, Sig.=.030) showed a statistical difference between the two dining occasions. In the case of emotional response, the significant differences only occurred on group $4(\mathrm{t}=2.658, \mathrm{df}=19$, Sig. $=.016)$ and group $6(\mathrm{t}=-4.379, \mathrm{df}=19$, Sig.=.000). Whereas in behavioral intention, group $1(t=3.584, d f=19$, Sig.=.002) group $4(t=4.579, d f=19$, Sig.=.016), group $6(\mathrm{t}=-1.279, \mathrm{df}=19$, Sig. $=.005)$ and group $7(\mathrm{t}=2.299, \mathrm{df}=19$, Sig. $=.033)$ also showed a significant difference between the two dining events.

From the Anova test results, we noticed that in the case of dining with a friend/s, it seemed that the subjects were not so sensitive with the manipulation of interior element as there was no statistical difference between each of the groups. Referring to one of the behavior-environment relationship theories, stimulation theory (Kopec, 2006), we can also say that none of the groups could benefit more from the stimulation of its restaurant atmosphere. Such finding could also imply that casual relationships between customers may not need a specially conditioned interior environment to support their dining motives. From the perspective of restaurant design, the insignificant different responses of the subjects toward any of the groups may also be resulted from the fact that all the conditions were considered acceptable to dine with a friend/s.

In the case of dining with a special friend, the subjects of group 6 that rate a restaurant with monochromatic colors, dim lighting and plain décors performed the highest positive perceived, emotional and behavioral value compared with almost the rest of the groups. This means that such environmental condition was effective to stimulate the subjects in the way they perceive, feel and behave towards the restaurant when dining on a date. They preferred such atmosphere probably because all the elements were not visually stimulating as the colors' energy were peaceful, subtle because of a lack of contrast of hue, the light level was moderately low, and the décors were much simpler, which may be desired for a couple to have a relaxing and romantic chat.

Of all these elements, the lighting characteristic is the most effective one to stimulate the subjects' motivation for such dining motive. A moderately low level of light along with the application of complementary colors or of elaborate décor could still be effective to support that dining occasion as shown in group 2, group 8 , which are not significantly different from group 6 in most of the variables evaluated, except in group 5 (using bright light), but since its $P$ value is .052 , which is very close to significance score (.05), this group may be considered different with group 6 .

From this Anova test result in some variables, we can prove that atmospheric quality as created by the three elements used in this experiment has effects on the subjects' 
perception of sociability, emotional, and behavioral intention, which are consistent to Mehrabian and Russell theory.

In addition, the perceived sociability and emotional response towards the restaurant interiors seemed to have a strong relationship as indicated by their very similar results. In the case of behavioral intention the subjects seemed not to be very strongly influenced by what they perceived and felt as indicated by a slight different result with that of the previous variables. However, this finding can still be considered consistent with the previous statements of Woodruff (1997); Parasuraman and Grewal (2000); Cronin et al. (2000) as quoted by Liu et al. (2009) stating that perceived values have effects on behavioral intentions.

From the T-test result we could infer that between the two dining motives in group 1, group 4, group 6, and group 7, the subjects responded significantly different. However, with the output of the Anova test we can infer more consistently why the differences occurred. For example, we notice that group 1 was not preferable for dining with a special friend, as well as group 4 and group 7 . Besides that, these groups were statistically different from group 6 in the Anova test in the case of dining with a special friend, group 1 probably was too bright, and the elaborate décor was visually too striking, whereas in group 4 although the lighting was dim but it seemed that the complementary color and elaborate décor might be too stimulating. Group 7 was not preferable probably because the complementary colors and the bright lighting was not suitable for dining on a date. In fact, when these two elements were used effectively, they may become a strategic element to stimulate people, otherwise people will easily feel annoyed.

\subsection{Conclusions}

The study of interior elements and its effect on social behavior is still immature. Regardless of this study's weaknesses, such initiative shares one of the lacking reference that offers evidence on the fact that colors, lighting and décor do influence social dining behavior. The colors, lighting and décors, as experimental stimuli were defined by qualitative approach, because this study is still considered exploratory. Therefore this study contributes imperfect implication to the profession. In the future, when the similar stimuli are used, a more standardized measure may be suggested to expect broader practical implication. In addition, a more direct of research considering this research's particular result (e.g. lighting) could be suggested, for instance: some measurable qualities of lighting, for instance illuminance level, types of luminaires and luminance distribution may be considered for future study. Beside eating-places observed in this study other commercial places where more specific sociability may also profoundly occur could also be considered, as this study found that it influenced differently to the way people select dining atmosphere. The social relationships we studied as mediator for social dining were common, and there are still many more complex relationship people may create, whose social dining mediation-role 
may lead to a more sophisticated need of restaurant atmosphere. In addition, we may question how cultural influences (Rozin, Kruzer, \& Cohen, 2002; Prescott, Young, O'Neill, Yau, \& Stevens, 2002) or any other personal attributes of the subjects moderate their relationship and influence the way they choose a restaurant. A similar question may be raised according to personal differences of age, religion or lifestyles respectively. All these curiosities are crucial as they are prospective consumers for service business industries. Design scientists are in need for more clues from them to create guidelines for designers, who may need a distinctive modus operandi to explore, as how this study has introduced for studying the effects of environmental stimuli on human social behavior in a non-dining setting.

\section{Acknowledgements}

We would like to thank Drs. Andriyanto Wibisono, MDs. and Dr. Pribadi Widodo, MDs. for their support to this study by providing a room and some equipment, at the HumanEnvironment relationship research unit, Faculty of Fine Art and Design, Institute of Technology, Bandung, Indonesia.

\section{References}

Azizi, T. (2010). The Dining Experience. Canada. The University of Lethbridge

Cheng, H., Lee, K., \& Lee, H. (2007). Color Preference of the Korean Elderly. International Association of Societies of Design Research, The Hongkong PolytechnicUniversity.

Diane, S. (2005). Environmental distinctions: the discriminating dining environment. Les Cahiers du CICLas. 6, 557.

Flanagan, C. (1999). Early Socialization: Sociability and attachment. London: Routledge Modular Psychology Series.

Gifford, R. \& Gallagher, M.B. (1985). Sociability: Personality, Social Context, and Physical Setting. Journal of Personality and Social Psychology, 48, 1015-1023.

Junko, I., Masashi, N., \& Minoru, M. (2006). The Influence of colors on the psychological image of the wooden interior: application of the image analysis in consideration of the accent color. Zairyo, 55, 373-377.

Kopec, D. (2006). Environmental Psychology for Design. New York: Fairchild Publications, Inc.

Lin, I.Y. (2004). Evaluating servicescape: the effect of cognition and emotion. Hospitality Management, 23, 163178.

Liu, Y. \& Jang, S. (2009). The Effects of Dinning Atmospherics; An extended Mehrabian-Russel model. International Journal of Hospitality Management, 28, 494-503. 
Macht, M., Meininger, J., \& Roth, J. (2005). The Pleasures of Eating: a Qualitative Analysis. Journal of Happiness Studies. 6,137-160

Mehrabian, A., and Russel, J.A. (1974). An Approach to Environmental Psychology. Cambridge, MA: MIT Press

Oldenburg, R. (1997). Great Good Place, Cambridge: Da Capo Press

Pine, J \& Gilmore J.H. (1999). The Experience Economy. Boston: Harvard Business School Press

Prescott, J., Young, O., O'Neill, L., Yau, N.J.N., \& Stevens, R. (2002). Motives for food choice: a comparison of consumers from Japan, Taiwan, Malaysia and New Zealand. Food Quality and Preference, 13, 489-495.

Rozin, P., Kruzer, N.C., \& Cohen, A. (2002). Free Associations to "food": the effects of gender, generation, and culture. Journal of Research in Personality, 36, 419-441.

Scott, N., Laws, E., \& Boksberger, P. (2009). The marketing of Hospitality and Leisure Experiences, Journal of Hospitality Marketing \& Management, 18, 99-110.

Wansink, B. (2006). Mindless Eating: Why we eat more than we think. New York: Bantam Books

Wheldall, K. (1975). Social Behavior: Key problems and social relevance. London: Methuen 